\title{
DOSSIE
}

\section{A Autoavaliação e Autodefinição de Carolina Maria de Jesus na obra Quarto de Despejo: diário de uma favelada}

\author{
Carolina Maria de Jesus' Self-Assessment \\ and Self-Definition in the work \\ Quarto de Despejo: diary of a favela
}

\author{
Cristiane da Rosa Elias \\ Mestranda em História e Religiões na UNICENTRO \\ cristianeeliasuerj@yahoo.com.br
}

RESUMO: O presente artigo pretende analisar a obra "Quarto de Despejo" de 1960 de Carolina Maria de Jesus a partir de uma visão interseccional proposta pelo feminismo negro. Com isso, objetivamos perceber como o olhar oposicional se faz presente na obra de Carolina de Jesus e como essa é uma das representações de mulheres negras nesse contexto histórico. Para isso, utilizaremos as categorias de análise propostas por Patricia Collins de autoavaliação e autodefinição das mulheres negras, pois, na obra em questão, temos as memórias de Carolina, mulher negra e periférica que constantemente avalia sua vida e seu cotidiano precário; sem travamentos, enxergando, definindo e escrevendo a realidade do seu grupo social e, dessa maneira, autoavaliando e autodefinindo suas memórias. Dessa forma, caminhamos para perceber o potencial transformador que o olhar oposicional de mulheres negras, apoiado em suas realidades e contextos diversos, podem dizer sobre si e sobre o seu coletivo.

PALAVRA-CHAVE: Maria Carolina de Jesus. Feminismo negro. Olhar oposicional.

ABSTRACT: The present article intends to analyze the work "Quarto de Despejo" from 1960 by Carolina Maria de Jesus from an intersectional view proposed by black feminism. With this, we aim to understand how the oppositional look is present in the work of Carolina de Jesus and how this is one of the representations of black women in this historical context. For this, we will use the categories of analysis proposed by Patricia Collins of self-assessment and self-definition of black women, because, in the work in question, we have the memories of Carolina, a black and peripheral woman who constantly assesses her life and her precarious daily life; without crashes, seeing, defining and writing the reality of your social group and, in this way, self-evaluating and self-defining in these memories. In this way, we walk to realize the transformative potential that the oppositional gaze of black women, based on their different realities and contexts, can say about themselves and their collective.

KEYWORDS: Maria Carolina de Jesus. Black feminism. Opositional look. 
Revista do Corpo Discente do Programa de Pós-Graduação em História da UnB

EM TEMPO DE HISTóRIAS | Brasília-DF | n. 36 | p. 151-158 | jan./jun. 2020.

ISSN 2316-1191

Atribuímos uma importância fundamental ao fenômeno da linguagem. É por essa razão que julgamos necessário este estudo, que pode nos fornecer um dos elementos de compreensão da dimensão para-o-outro do homem de cor. Uma vez que falar é existir absolutamente para o outro. (FANON, 2008, p. 33)

Após um ano do fim do sistema escravista surge a primeira República no Brasil, entretanto, o novo sistema em nada melhorou a vida das negras e negros descendentes do período escravista, mas contribuiu para marginalizar politicamente, socialmente, psicologicamente e economicamente esses sujeitos. Nesse novo regime, somou-se o racismo científico e as teorias de branqueamento, que passaram a ser a forma de estruturar a não adequação do negro e seu corpo, à construção da nova nação. Também foi nesse momento que mulheres e homens negros dos grandes centros como São Paulo, Rio de Janeiro, Curitiba, entre outros, foram se mobilizar politicamente na busca de melhores condições sociais.

Em São Paulo, apareceram o Club 13 de Maio dos Homens Pretos (1902), o Centro Literário dos Homens de Cor (1903), a Sociedade Propugnadora 13 de Maio (1906), o Centro Cultural Henrique Dias (1908), a Sociedade União Cívica dos Homens de Cor (1915), a Associação Protetora dos Brasileiros Pretos (1917); no Rio de Janeiro, o Centro da Federação dos Homens de Cor; em Pelotas/ RG, a Sociedade Progresso da Raça Africana (1891); em Lages/SC, o Centro Cívico Cruz e Souza (1918). (DOMINGUES, 2007: 103)

Além dessas associações, foram publicados vários periódicos que tinham como um de seus objetivos a denúncia das mazelas que afetavam a população negra e os regimes de segregação racial, que estava presente em diversas cidades do país (DOMINGUES, 2007:105). Posteriormente produzido também em meio acadêmico, como podemos observar com Beatriz Nascimento, Lélia Gonzalez, Virginia Leone Bicudo, Neuza Santos, entre outros com pensamentos e reflexões sobre a complexidade identitária da população negra e a sofisticação do "racismo múltiplo" (RATTS, 2006, p. 50)

Beatriz Nascimento sintetiza esse momento como; "a democracia racial brasileira talvez exista, mas em relação ao negro inexistente" (NASCIMENTO, 1974, p. 94) e assim dialoga com a construção do pensamento freyriano que perpassa diversos pensamentos, reflexões, escritos, modos de ser e agir em relação a vivência negra como se essas historicidades fossem homogêneas. A não homogeneidade das vidas negras no Brasil, como em diáspora, torna as pesquisas e reflexões sobre mulheres e homens negros em constante construção de suas histórias e da história cada vez mais complexa e desafiadora na atualidade.

Apesar de Carolina de Jesus não fazer parte desses espaços de construção acadêmica, pois, enquanto mulher negra periférica, não estava nesses círculos e centros, a mesma foi uma das muitas faces desse movimento negro no Brasil. Existiu considerável participação de mulheres negras nesses movimentos, entretanto, Carolina Maria de Jesus era a outra verdade de mulheres negras dentro do movimento político, tanto negro quanto nacional. Pois, mesmo o movimento político dos negros nesse período estando com força e organizado, a demanda era grande. Refletindo a partir do livro "Frente Negra Brasileira: depoimentos" - de Mário Barbosa, percebemos que a grande maioria que compunha e se beneficiava dessas organizações, eram homens e mulheres negros solteiros ou casados. 
Partindo da noção proposta por Judith Butler de que não existe uma única representação de mulher; Durante muito tempo o movimento feminista quis compelir e, mediante a demanda do poder jurídico, produziu sujeitos enquadrados para poder assim exercer seu poder sobre esses corpos desviantes (BUTLER, 2008). Dessa forma, compreendermos que dentro da ideia de mulheres negras, existem diversas representações e uma delas é Carolina de Jesus, sendo uma das verdades político-sociais de mulheres negras.

Imersa nesse contexto e partindo dessa visão teórica, nasce a escritora Carolina Maria de Jesus em Sacramento, Minas Gerais, no ano de 1914. Seus pais migraram para a cidade no início das atividades pecuárias na região; movimento típico com o pósabolição sem projeto. Em 1923, ela estudou no colégio Allan Kardec, primeira escola espírita do Brasil. Instituição em que as crianças pobres eram mantidas por pessoas influentes da sociedade. E os estudos de Jesus foram mantidos por Maria Leite Monteiro de Barros, para quem a mãe ${ }^{1}$ de Carolina trabalhava como lavadeira, entretanto, Carolina de Jesus estudou somente por dois anos e continuou de forma autônoma a construção de seu letramento.

Em 1947, Carolina de Jesus mudou-se para São Paulo, no início do processo de modernização que tomava a capital Paulista entre outras capitais, com seu novo discurso de nação. Que modernizava seus centros comerciais e suas vitrines para apresentá-los ao mundo, ditando novas formas que o corpo feminino e masculino precisava se enquadrar, como também trazia novos padrões de comportamento e higiene. Entretanto, essa renovação não teve um projeto que levasse em consideração as camadas mais pobres da sociedade e principalmente a população negra do país, que ainda estava se encaixando nas novas formas de exclusão e exploração de seu trabalho. Com isso, irão se organizar as margens do centro das cidades, as primeiras favelas do país, com suas faltas de estrutura, saneamento e dignidade ${ }^{2}$.

Entre 1945 a 1964, temos o fim da "Era Vargas" e o início da segunda República do Brasil. Nesse contexto, Carolina Maria de Jesus, mulher negra que viveu com seus três filhos; João José de Jesus, José Carlos de Jesus e Vera Eunice de Jesus Lima, na favela do Canindé ${ }^{3}$, inicia a escrita de suas memórias, do seu cotidiano. Aparecem suas reflexões políticas, sociais e raciais, tudo em cadernos encontrados entre os lixos que recolhia pela capital. Essas memórias darão origem ao seu primeiro livro publicado em 1960, "Quarto de despejo: diário de uma favelada". Dessa forma, podemos compreender como uma literatura memorialista, que fala de si, também fala de um coletivo, pois, "cada memória individual é um ponto de vista sobre a memória coletiva, [que] este ponto de vista muda conforme o lugar que ali eu ocupo" (HALBWACHS, 1990, p. 51 apud

\footnotetext{
${ }^{1}$ Não encontrei na pesquisa que fiz, informações sobre o nome dos pais de Carolina Maria de Jesus, que seria muito interessante para possíveis conjecturações sobre a memória da escravidão presente na sua origem família e posteriormente em sua obra.

2 Beatriz Nascimento desenvolve um estudo na década de 1980 compreendendo a formação das favelas como uma continuidade dos quilombos do período escravista e propõem compreende-los não mais como conceitos únicos e sim, a partir de "uma linha de continuidade entre os sistemas sociais organizados pelos negros quilombolas e os assentamentos sociais nas favelas". (RATTS, 2006:57)

${ }^{3}$ Que se formou no início dos anos de 1950, localizada as margens do Rio Tietê, na cidade de São Paulo, e hoje não existente mais.
} 
COSTA, J. C.; ALVES, Lourdes Kaminski. 2010, p. 203). Essa é escrita a partir de um interesse e, em diálogo com seu lugar temporal, numa forma de estruturar o seu universo particular.

Carolina ainda em vida, publicou mais três livros; "Casa de alvenaria: diário de uma ex-favelada", "Pedaços da fome" e "Provérbios". Após sua morte, em 1977, aos 62 anos de idade, foram publicados; "Diário de Bitita", "Meu estranho diário", "Antologia pessoal", "Onde estaes felicidade?" e "Meu sonho é escrever". Entretanto, nenhuma outra obra da autora fez tanto sucesso quanto "Quarto de despejo", produção bem demarcada historicamente, já que entre os anos 1950 e 1960 as narrativas de denúncia foram foco da mídia, dos escritores e consequentemente do público ${ }^{5}$.

A escritora foi evidenciada na época, pelo jornalista Audálio Dantas. Em 1960, ele organizou e apresentou a primeira edição ao público. Na apresentação da obra, Dantas retratou o contexto de denúncia acima mencionado:

A história da favela que eu buscava estava escrito em uns vinte cadernos encardidos que Carolina guardava em seu barraco. Li, e logo vi: repórter nenhum, escritor nenhum poderia escrever melhor aquela história - visão de dentro da favela. (DANTAS, 1960:3)

O livro, "forte e original" (DANTAS, 1960, p. 4 apud. JESUS, 1960)", gerou muita polêmica tanto pelo número de exemplares vendidos dentro e fora do país, superando as tiragens que normalmente saíam, como pelo assunto abordado que tomou lugar em jornais, revistas, rádio e televisão e, posteriormente, pela crítica de escritores renomados na época.

O sucesso do livro - uma tosca, acabrunhante e até lírica narrativa do sofrimento do homem relegado à condição mais desesperada e humilhante de vida - foi também o sucesso pessoal de sua autora, transformada de um dia para outro numa patética Cinderela, saída do borralho do lixo para brilhar intensamente sob as luzes da cidade. (DANTAS; 1960:4)

Dessa forma, a ideia aqui é olharmos essa autora e sua obra não somente pela perspectiva da vulnerabilidade cotidiana, mas sim, do seu olhar crítico "oposicional” do contexto histórico, enquanto mulher negra e mãe solteira a margem da sociedade. bell hooks ${ }^{6}$ pontua que o olhar é um lugar de resistência para pessoas negras colonizadas e esse mesmo olhar pode ser documentado, pelo ser considerado dominado e assim construir seu agenciamento e consciência.

Os espaços do agenciamento existem para pessoas negras, na medida em que podemos tanto interrogar o olhar do Outro quanto olhar em retrospectiva, e também olhar um para o outro, nomeando o que vemos. O "olhar" foi e é um local de resistência para pessoas negras colonizadas, em escala global. Os grupos subordinados nas relações de poder aprendem, por experiência, que existe um

\footnotetext{
${ }^{4}$ Segundo a página Literafro; o portal de literatura afro-brasileira, a obra "Quarto de despejo" publicado em 1960 teve na sua primeira edição trinta mil exemplares vendidos, chegando a cem mil na segunda e terceira edição. Além de esse ter sido traduzido para treze idiomas em mais de quarenta países.

5Transgressor para o período, pois uma mulher negra publicar um livro e esse ser um dos livros mais vendidos dentro e fora do país visto que escrever e publicar livros era e ainda é um sistema de conhecimento e poder.

${ }^{6}$ bell hooks é o pseudônimo de Gloria Jean Watkins que prefere que esse seja escrito em minúscula para a atenção esteja em sua mensagem não em seu nome.
} 
olhar crítico que "olha" para documentar, e que é oposicional. Na luta da resistência, o poder do dominado para afirmar o agenciamento, reivindicando e cultivando a "consciência", politiza as "relações com o olhar" - aprende-se a olhar de certa maneira, para que se possa resistir. (HOOKS, 2017:485).

O olhar oposicional de Carolina Maria de Jesus está imerso em toda sua obra, tanto ao perceber e analisar o "Outro", como também a si mesmo. Acreditamos que olhar para si mesmo, a partir das demandas específicas do indivíduo oprimido é uma forma de produção de conhecimento e de auto cuidado, que é transgressor dentro da estrutura colonizadora vivida pelas negras e negros em diáspora. Beatriz Nascimento observa esse movimento como sendo uma forma de reconstruir e buscar a imagem de si, perdida no processo escravista. (RATTS, 2006, p. 65-66).

Pensando também esse movimento, Carolina de Jesus, relata a vivência na favela do Canindé, descrevendo a violência existente nas relações entre os moradores ${ }^{7} \mathrm{e}$ a desumanidade que vivenciam cotidianamente, devido ao descaso político que foram colocados, pois, Carolina em muitos momentos revela a atuação de políticos que aparecem em períodos de eleição, doam coisas e ficam a par da desumana condição de vida no local e, logo após, ganhando seus cargos, nunca mais voltam e também não solucionam a situação da favela. A autora expõe nomes e sobrenomes de diversos políticos em seu livro. Tanto os que apareceram com promessas, quanto os que nunca apareceram, mas que estavam em noticiários. Sua narrativa em diversos momentos, questiona a postura de políticos da época, suas faltas e negligências, às vezes com certo humor e analogias;

...o Dr. José Torre Netto. Bom médico. E falamos de políticos. Quando uma senhora perguntou-me o que acho do Carlos Lacerda, respondi conscientemente: -- Muito inteligente. Mas não tem educação. É um político de cortiço. Que gosta de intriga. Um agitador. (JESUS; 1960:12) ${ }^{8}$

Para além dessas questões, Carolina Maria de Jesus constantemente se autodefine e autoavalia em sua obra como no trecho; "2 de maio de 1958. Eu não sou indolente. Há tempos que eu pretendia fazer o meu diário. Mas eu pensava que não tinha valor e achei que era perder tempo" (JESUS, 1960, p. 25). Percebemos uma refutação da autora sobre a imagem que ela sabe que existe sobre si, além de um processo de percepção da importância de escrever seu diário. Como também na passagem; "O Brasil precisa ser dirigido por uma pessoa que já passou fome. A fome também é professora. Quem passa fome aprende a pensar no próximo, e nas crianças." ((JESUS, 1960, p. 26) Carolina de Jesus avalia e sugere uma mudança na politica a partir da percepção de sua realidade.

O significado sociológico de autodefinição e autoavaliação proposto por Patricia Hill Collins, que mobilizamos para compreender esse voltar para si e para os escritos de Carolina de Jesus, consiste basicamente em desafiar as imagens estereotipadas,

\footnotetext{
${ }^{7} \mathrm{~A}$ autora relata muitos casos de violência doméstica, alcoolismo, humilhações que não irei aprofundar aqui, mas que é muito rico para uma analise da sociedade de 1940 e 1950 como também das condições da marginalidade.

${ }^{8}$ Todas as citações do livro da autora Carolina Maria de Jesus estão transcritas conforme a obra.
} 
construídas sobre mulheres negras ${ }^{9}$ no decorrer dos tempos pela história, mídia e senso comum (autodefinição). E através disso, enfatizar imagens autênticas dessas mulheres negras, dentro de suas realidades e comunidades, autoavaliação (COLLINS, 2016, p. 102). Podemos perceber esse movimento na obra de Carolina Maria de Jesus em diversos momentos, entretanto, separamos dois para expor e explorar, por agora:

Quando um politico diz nos seus discursos que está ao lado do povo, que visa incluir-se na politica para melhorar as nossas condições de vida pedindo o nosso voto prometendo congelar os preços, já está ciente que abordando este grave assunto ele vence nas urnas. Depois divorcia-se do povo. Olha o povo com os olhos semicerrados. Com um orgulho que fere a nossa sensibilidade. (JESUS, 1960:34)

...Eu classifico São Paulo assim: O Palácio, é a sala de visita. A Prefeitura é a sala de jantar e a cidade é o jardim. E a favela é o quintal onde jogam os lixos. (JESUS, 1960:28)

A dominação sempre envolve a objetificação do dominado; todas as formas de opressão implicam a desvalorização da subjetividade do oprimido (BRITTAN \& MAYNARD, 1984:199 apud COLLINS, 2016:105), podemos perceber esse movimento na primeira citação, pois, os políticos coisificam esses sujeitos conforme lhes convém, respaldados pela estrutura de dominação. Carolina de Jesus percebe esse movimento costumeiro e, relata-o exercendo e construindo sua autodefinição, desafiando esse lugar que acreditam os dominadores - devem estar todos os favelados, principalmente as mulheres negras. Com a segunda citação, podemos acompanhar a percepção da autora e seu constante olhar crítico e macro do universo político, com seu centro e sua periferia. Analisando essas passagens e trazendo essas relações, podemos perceber o quanto o conhecimento crítico não está somente nas academias e nos "grandes salões"10, mas também, no "quarto de despejo".

Em diálogo com a proposta de hooks e Collins, percebemos que Carolina de Jesus reflete em diversos momentos sobre sua condição de pessoas negra;

13 de Maio. Hoje amanheceu chovendo. É um dia simpático para mim. É o dia da Abolição. Dia que comemoramos a libertação dos escravos.

...Nas prisões os negros eram bodes espiatórios. Mas os brancos agora são mais cultos. E não nos trata com despreso. Que Deus ilumine os brancos para que os pretos sejam feliz. (JESUS, 1960:27)

Eu escrevia peças e apresentava aos diretores de circos. Eles respondia-me: - É pena você ser preta. Esquecendo eles que eu adoro a minha pele negra, e o meu cabelo rustico. Eu até acho o cabelo de negro mais iducado do que de branco. Porque o cabelo de preto onde põe, fica. É obediente. E o cabelo de branco, é só dar um movimento na cabeça ele já sai do lugar. É indisciplinado. Se é que existe reincarnações, eu quero voltar sempre preta. (JESUS, 1960:58)

No primeiro fragmento, podemos perceber uma reflexão profunda da autora, pois, ela consegue compreender o quão ligada está a condição do povo negro às aspirações dos

\footnotetext{
${ }^{9}$ Patricia Hill Collins propõem e trabalha com essa categoria de analise pensando a realidade de mulheres afro-americanas, mas nesse momento estamos fazendo uma leitura para a realidade de mulheres afrobrasileiras.

${ }^{10}$ Uma das analogias que a autora faz recorrentemente é do centro da cidade e Assembleia dos políticos como sendo o salão de festa, sala de visita enquanto que a favela é o quarto de despejo dessa cidade.
} 
brancos, que detém o poder político e econômico do país, como também de contribuir na construção de nossas identidades, no nosso cotidiano. Dialogando assim, mesmo sem acesso a essas leituras, com as linhas de pensamento de Stuart Hall (1994) e Frantz Fanon (1952) que já escreviam sobre a força intrínseca dos brancos na construção do ser negro.

O erro não é conceituar essa 'presença' em termos de poder, mas localizar esse poder como totalmente externo a nós - como força extrínseca, cuja influência pode ser descartada, como a serpente troca de pele.” (HOOKS, 2017:484-485 apud HALL, 1994)

[...] os movimentos, as atitudes, os olhares do Outro me fixara ali, no mesmo sentido que uma solução química é fixada por um corante. Fiquei indignado; exigi uma explicação. Nada aconteceu. Eu quebrei. Agora os fragmentos foram reunidos novamente por um outro self. Esse 'olhar', a partir de - por assim dizer - um lugar do Outro, nos fixa, não somente em sua violência, hostilidade e agressão, mas também na ambivalência de seu desejo. (HOOKS, 2017:485 apud FANON, 1967)

Já no segundo trecho, podemos perceber, dentro da compreensão de autoavaliação, a construção positiva e autêntica que Carolina tem de si, mesmo diante dos estereótipos negativos construídos do ser negro. Apresentando uma resposta em que se mostra orgulhosa de seus traços identitários, de forma a naturalizados positivamente. No entanto, lembremos, que no contexto que a autora escreveu essa passagem, não tínhamos os discursos de afirmação identitária postas de forma afirmativa. Já que o movimento Black is beautiful, que se inicia nos Estados Unidos na década de 1960, ainda não estava posto de forma consistente e organizada. O que tínhamos eram Carolinas que ressignificavam suas estéticas a partir de suas inquietações. A autora transforma assim, o estereótipo que foi construído para ser negativo, em algo autêntico e ousado, com isso, a autoavaliação das mulheres negras desafia o conteúdo de imagens controladoras externamente definidas. (COLLINS, 2016:104) [Grifo nosso].

Já encaminhando para o fim dessa proposta, Carolina Maria de Jesus em seu diário escreve suas memórias e com isso supera o lugar de opressão, de estereótipos negativos e de não lugar, pois, externaliza sua vivência, analisa o mundo em que vive, tanto de maneira micro quanto macro e, apresenta outras formas de enxergar os fatos ordinários da vida. Mostra assim, uma versão de mulher negra para além da sexualização, do cuidado maternal (babá) e da desumanização que a sociedade construiu e a mantém a partir de suas sofisticações. E também ressignificando os estereótipos que são usados para controlar grupos dominados (COLLINS, 2016, p. 104), apresentando-se enquanto uma mente pensante e desestruturante do sistema de dominação.

Carolina de Jesus não é um ser homogêneo como geralmente se espera, ela apresenta também contradições naturais da vida. Em alguns momentos reproduz ideários burgueses, como também crença de que a favela em si é que desvirtua as pessoas e não que as condições postas que eram o problema, todavia, essa também era uma forma da mesma se distinguir-se dentro do universo que vivia e sobrevivia. Mesmo diante desses raciocínios, ela nos apresenta uma de muitas representações de mulheres negras colonizadas dentro de seus contextos históricos. O olhar oposicional, a autodefinição e autoavaliação estão presentes não só nos trechos separados, mas no ato de Carolina Maria de Jesus escrever suas memórias. 
O livro de Carolina Maria de Jesus é aqui utilizado como fonte de análise de uma conjuntura história do Brasil, portanto, escolhemos a dimensão sócio-histórica como possibilidade hermenêutica. A forma como a obra repercutiu, nos apresentou a inovação discursiva que a autora trazia para o país e para o mundo sobre o Brasil. Apresenta os percalços políticos e as vulnerabilidades sociais que a nação passava e, foi tão marcante no período pré-ditadura como também é fonte para pensarmos a abrangência e complexidade da construção intelectual do movimento dos negros no Brasil.

Entendemos, portanto, que visitar e analisar a literatura e o pensamento de autoras negras nacionais nos permite enxergar a importância de suas contribuições e perspectivas para compreensão das contradições na sociedade brasileira, da história nacional como discurso antioficial, e também dos diferentes olhares de mulheres negras sobre a política.

\section{Referências}

BUTLER, Judith. "Mulheres" como sujeito do Feminismo. In: Problemas de Gênero: feminismo e subversão da identidade. Rio de Janeiro: Civilização Brasileira, 2008. p. 17-48.

BARBOSA, Márcio. Frente Negra Brasileira: Depoimentos. Editora: Quilombhoje, 1998. Carolina Maria de Jesus - Literatura Afro-Brasileira. Literafro, 2019. Disponível em: <http://www.letras.ufmg.br/literafro/autoras/58-carolina-maria-de-jesus> Acesso em: 13 de maio de 2019.

COLLINS, Patricia Hill. Aprendendo com a outsider within: a significação sociológica do pensamento feminista negro. Revista Sociedade e Estado, Brasília, Volume 31, Número 1, p. 99-127, 2016.

COSTA, J. C.; ALVES, Lourdes Kaminski. Representações da memória na literatura e na cultura. Investigações (UFPE. Impresso), v. 23, p. 187-210, 2010.

DOMINGUES, Petrônio José. Movimento negro brasileiro: alguns apontamentos históricos. Tempo. Revista do Departamento de História da UFF, v. 12, p. 113-136, 2007.

FANON, Frantz. Pele negra, máscara brancas. Salvador: EDUFBA, 2008.

hooks, bell. O olhar oposicional: espectadoras negras. In: BRANDÃO, Izabel; CAVALCANTI, Ildney; COSTA, Claudia de Lima; LIMA, Ana Cecília Acioli. (Org.) Traduções da Cultura: Perspectivas Críticas Feministas (1970-2010). Florianópolis: EDUFAL; Editora da UFSC, 2017. p. 483-509.

JESUS, Carolina Maria de. Quarto de despejo: diário de uma favelada. Organização e apresentação de Audálio Dantas. Rio de Janeiro: Livraria Francisco Alves, 1960.

NASCIMENTO, Beatriz. Por uma história do homem negro. Revista de Cultura Vozes. 68(1), p. 41-45, 1974.

RATTS, Alex. Eu sou Atlântica: sobre a trajetória de vida de Beatriz Nascimento. Imprensaoficial. São Paulo, 2006. 